\title{
THE ELECTROCHEMICAL BEHAVIOUR OF IRON IN STAGNANT AND STIRRED POTASSIUM CARBONATE-BICARBONATE SOLUTIONS IN THE $0-75^{\circ} \mathrm{C}$ TEMPERATURE RANGE
}

\author{
C. R. Valentini and C. A. Moina \\ Instituto Nacional de Tecnología Industrial (INTI), Sector Electroquímica Aplicada, C. C. 157, \\ 1650 San Martín, Argentina \\ and \\ J. R. Vilche and A. J. Arvia \\ Instituto de Investigaciones Fisicoquímicas Teóricas y Aplicadas (INIFTA), C.C. 16, Suc. 4, \\ 1900 La Plata, Argentina
}

\begin{abstract}
The corrosion and passivation of polycrystalline iron electrodes in carbonate-bicarbonate solutions are studied in the $0-75^{\circ} \mathrm{C}$ temperature range. The influence of the solution ionic strength, stirring velocity, and potential scan rate on the electrodissolution of the base metal and the formation of both the prepassivating and the passivity surface layers are considered. The chemical dissolution of the prepassive film and the electroformation of the different surface compounds are discussed in terms of a complex reaction pathway involving both simultaneous and consecutive stages including the corresponding ionic equilibria.
\end{abstract}

\section{INTRODUCTION}

THE STUDY of the corrosion and passivation of iron in aqueous solutions containing carbonate is of importance in relation to the behaviour of the metal in contact with any aqueous system absorbing carbon dioxide. The publications on this subject are concerned mainly with the static iron samples ${ }^{1-11}$ and the influence of the hydrodynamic conditions. ${ }^{12-16}$ Iron samples in carbonate ion-containing solutions undergo different processes which also affect the susceptibility to an enhanced attack under either corrosion fatigue or stress corrosion cracking conditions. ${ }^{17-24}$

The voltammetric response of polycrystalline iron in potassium carbonate potassium bicarbonate electrolyte at $\mathrm{pH} 8.9$ and $25^{\circ} \mathrm{C}$ indicates that the main anodic current contribution which precedes the active to passive transition depends considerably upon the hydrodynamics of the electrochemical system. ${ }^{14}$ This aspect of the reaction, particularly the observed acceleration of the prepassive surface film dissolution as compared to that in borate-boric acid buffer at the same $\mathrm{pH},{ }^{25}$ is still unclear. Apparently, the active to passive transition of iron in alkaline carbonatebicarbonate electrolytes at $\mathrm{pH}$ slightly greater than seven implies the simultaneous and competitive formation on the metal of the hydrous iron oxide prepassive layer 


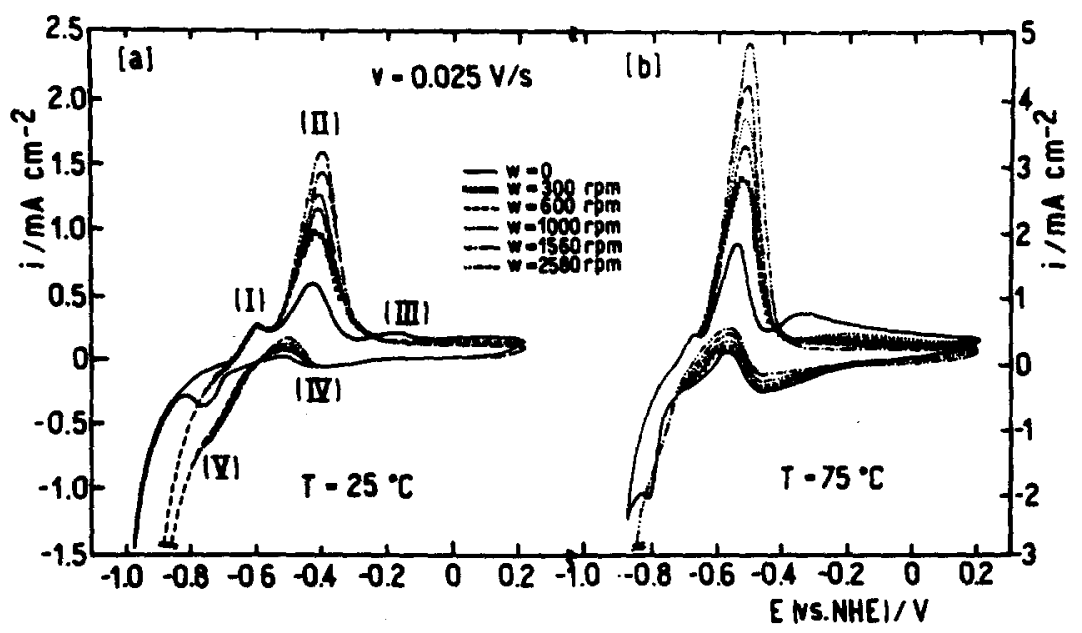

Fig. 1. The influence of $\omega$ and $T$ on the voltammograms run at $v=0.025 \mathrm{~V} / \mathrm{s}$ in $0.75 \mathrm{M}$ $\mathrm{KHCO}_{3}+0.05 \mathrm{M} \mathrm{K}_{2} \mathrm{CO}_{3}$ solution. (a) $T=25^{\circ} \mathrm{C}$; (b) $T=75^{\circ} \mathrm{C}$.

and a salt layer. These results in a complex structure of the metal-solution interface which reflects through the dependence of properties of the prepassive layer on the extent of each new phase formation process.

The present paper refers to the phenomenology of the active to passive transition of iron in carbonate-containing solutions paying particular attention to mass transport contributions in the overall anodic process. The interpretation of results is based upon the generalized reaction mechanism previously postulated ${ }^{26,27}$ to account for the electrochemical behaviour of the iron group metals in active corrosiun, active to passive transition and passivity onset in aqueous electrolytes of different composition.

\section{EXPERIMENTAL METHOD}

Runs were made with polycrystalline iron rotating disc electrodes. The experimental device was essentially the same as that described in previous publications. ${ }^{14.26,28}$ The RDEs were made from polycrystalline iron rods (Specpure, Johnson Matthey Chemicals Ltd, $5 \mathrm{~mm}$ diameter), axially embedded in PTFE cylinders. Before each electrochemical run the working electrode firstly was successively polished with 400 and 600 grade emery paper and later with a suspension of diamond paste in acetone. Finally, it was cathodized at $-1.0 \mathrm{~V}(\mathrm{NHE})$ during $10 \mathrm{~min}$ to obtain reproducible electroreduced iron surface. The potential of the working electrode was measured against a saturated calomel electrode provided with a Luggin capillary tip and properly shielded to avoid chloride ion diffusion into the electrolyte. Potentials in the text are given in the NHE scale. A large area platinum counterelectrode was employed.

The following electrolyte solutions were used: $2.5 \mathrm{M} \mathrm{KHCO}_{3}+0.167 \mathrm{M} \mathrm{K}_{2} \mathrm{CO}_{3}$ (solution A); $0.75 \mathrm{M}$ $\mathrm{KHCO}_{3}+0.05 \mathrm{M} \mathrm{K}_{2} \mathrm{CO}_{3}$ (solution B); $0.25 \mathrm{M} \mathrm{KHCO}_{3}+0.0167 \mathrm{M} \mathrm{K}_{2} \mathrm{CO}_{3}$ (solution C); 0.075 $\mathrm{M} \mathrm{KHCO}_{3}$ $+0.005 \mathrm{M} \mathrm{K}_{2} \mathrm{CO}_{3}$ (solution $\mathrm{D}$ ). The composition of the electrolytic solutions was such that the $\mathrm{KHCO}_{3} / \mathrm{K}_{2} \mathrm{CO}_{3}$ concentration ratio was 15 and $\mathrm{pH}$ 8.9. Most measurements were made with solution $\mathrm{B}$ while other solutions were employed to evaluate the influence of the ionic strength at a constant $\mathrm{pH}$. Solutions were prepared from analytical grade chemicals and bidistilled water, previously boiled to remove $\mathrm{CO}_{2}$.

Experiments were performed at $0,25,50$ and $75^{\circ} \mathrm{C}$. Voltammetric runs were made between the cathodic $\left(E_{\mathrm{s}, \mathrm{c}}\right)$ and the anodic $\left(E_{\mathrm{s}, \mathrm{a}}\right)$ switching potentials at potential sweep rates $(\nu)$ in the $0.001 \mathrm{~V} \mathrm{~s}-1 \leqslant$ 


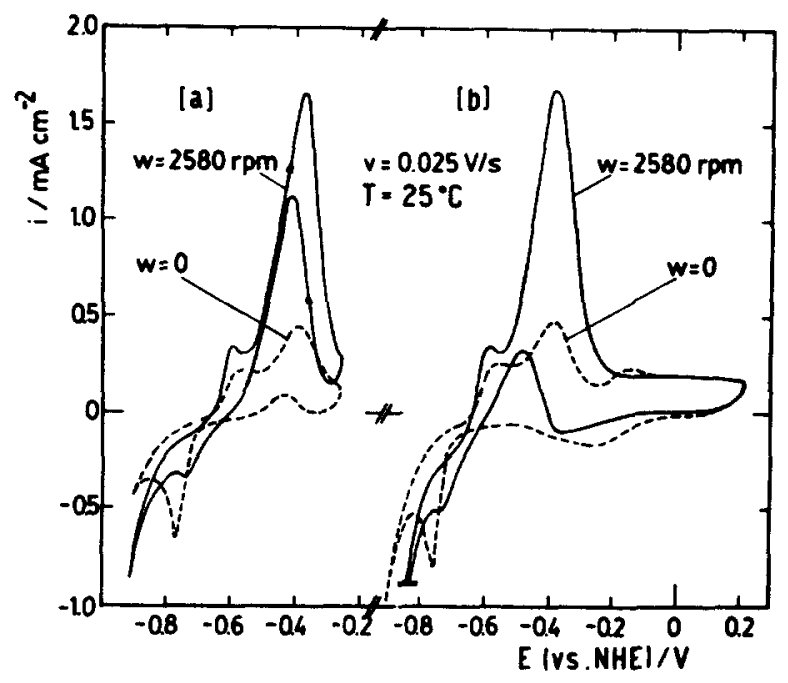

Fig. 2. The influence of $E_{\mathrm{s} . \mathrm{a}}$ on the voltammograms run at $\omega=0$ and $\omega=2580 \mathrm{rpm}$ in $0.75 \mathrm{M} \mathrm{KHCO}_{3}+0.05 \mathrm{M} \mathrm{K}_{2} \mathrm{CO}_{3}$ solution under fixed $v=0.025 \mathrm{~V} / \mathrm{s}, T=25^{\circ} \mathrm{C}$ and $E_{\mathrm{s} . \mathrm{c}}$ $=-0.90 \mathrm{~V}$. (a) $E_{\mathrm{s}, \mathrm{a}}=-0.25 \mathrm{~V}$; (b) $E_{\mathrm{s}, \mathrm{a}}=0.20 \mathrm{~V}$.

$v \leqslant 0.25 \mathrm{~V} \mathrm{~s}^{-1}$ range. The rotation speed of the $\mathrm{RDE}(\omega)$ was varied in the $0 \leqslant \omega \leqslant 2580$ rpm range. Scanning electron micrographs were obtained in a SEM-Philips 505/B with specimens previously subjected to bidistilled water and/or ethanol cleaning, dried and gold metallized. Energy dispersive X-ray andyses of the surface films were carried out using an EDAX-PV 9100/60 equipment, and electron-probe micro-analyses were made employing a Microspec WDX-2A apparatus.

\section{RESULTS}

Voltammograms run at $25^{\circ} \mathrm{C}$ between -0.98 and $0.23 \mathrm{~V}$ at $0.025 \mathrm{~V} \mathrm{~s}^{-1}$ in quiescent solution B (Fig. 1a) exhibit three anodic peaks (I, II and III) in the -0.65 to $-0.15 \mathrm{~V}$ range and two cathodic peaks, one rather poorly defined at $c a-0.4 \mathrm{~V}$ (peak IV) and another one at $c a-0.8 \mathrm{~V}$ (peak V). A relatively large increase in cathodic charge associated with the hydrogen evolution reaction is observed at potentials lower than $-0.85 \mathrm{~V}$. The rotation of the electrode produces remarkable changes in the height of peaks II, III, IV and V and an apparent depolarization of the cathodic reaction taking place at potentials more negative than $-0.6 \mathrm{~V}$. In the active to passive transition, both the charge and height of peak II increase considerably with $\omega$. but those of peak I appear independent of $\omega$. Under comparable perturbation conditions, the voltammetric characteristics remain qualitatively the same at $75^{\circ} \mathrm{C}$ (Fig. 1b), although for the latter the increase of both charge and height of peak II is about three times greater than those observed at $25^{\circ} \mathrm{C}$. Furthermore, the decrease in the cathodic polarization at potentials lower than $-0.6 \mathrm{~V}$ at $75^{\circ} \mathrm{C}$ caused by stirring is smaller than at $25^{\circ} \mathrm{C}$.

The electrochemical $E / i$ response during the negatively directed potential excursion also depends on $E_{\mathrm{s} . \mathrm{a}}$ (Fig. 2). When $E_{\mathrm{s} . \mathrm{a}}$ is preset at a potential just exceeding the potential range of peak II (Fig. 2a), the returning potential scan shows a reactivation of the electro-oxidation process related to peak II; the corresponding 


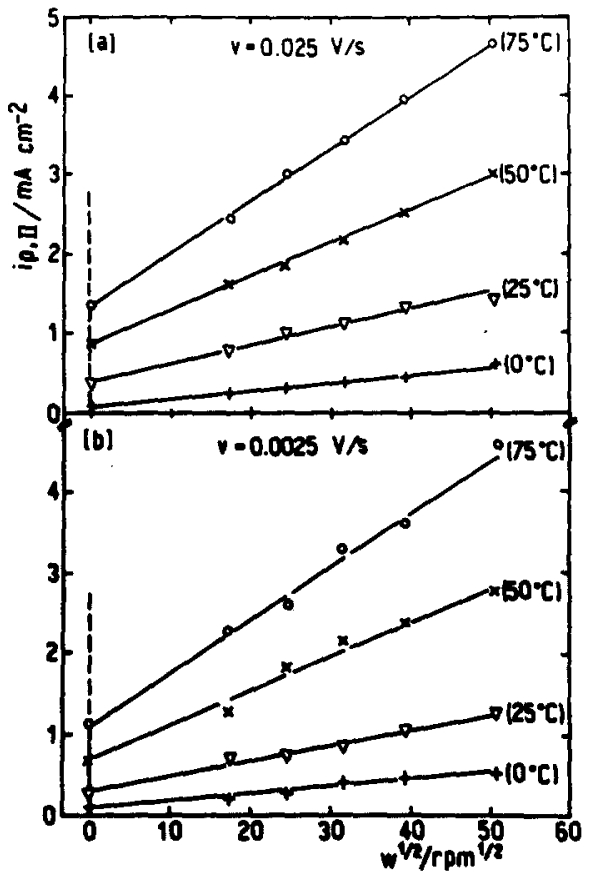

Fig. 3. The dependence of $\omega$ on $i_{\mathrm{p} .11}$ at $T=0(+), 25(\nabla), 50(\times)$ and $75(0)^{\circ} \mathrm{C}$ in 0.75 $\mathrm{M} \mathrm{KHCO}_{3}+0.05 \mathrm{M} \mathrm{K}_{2} \mathrm{CO}_{3}$ solution. (a) $v=0.025 \mathrm{~V} / \mathrm{s}$; (b) $v=0.0025 \mathrm{~V} / \mathrm{s}$.

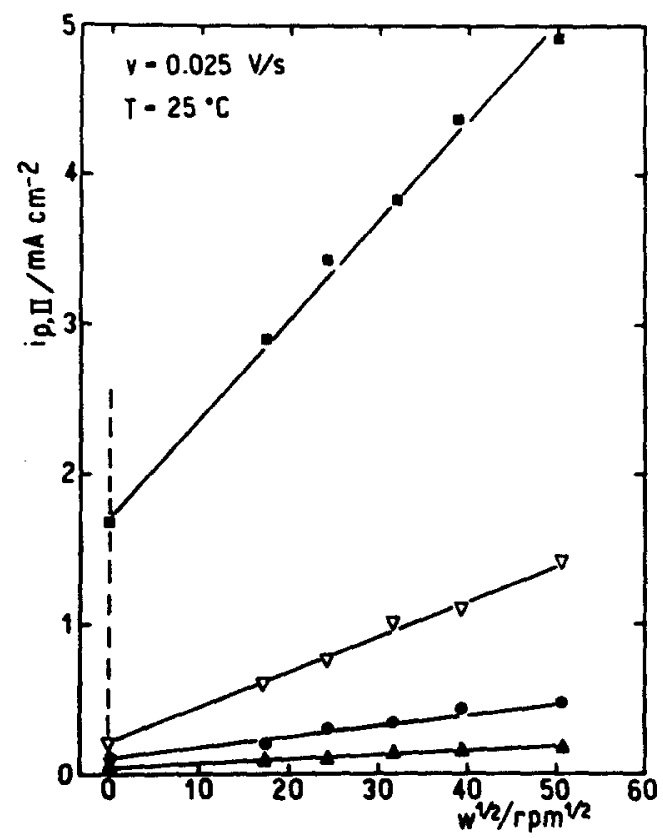

Fir. 4. The dependence of $\omega$ on $i_{\mathrm{p}, \mathrm{ll}}$ at $v=0.025 \mathrm{~V} / \mathrm{s}$ and $T=25^{\circ} \mathrm{C}$ at different ionic strengths, pH 8.9. (घ) $2.5 \mathrm{M} \mathrm{KHCO}_{3}+0.167 \mathrm{M} \mathrm{K}_{2} \mathrm{CO}_{3}$ : (v) $0.75 \mathrm{M} \mathrm{KHCO}_{3}+0.05 \mathrm{M}$ $\mathrm{K}_{2} \mathrm{CO}_{3} ;(\bullet) 0.25 \mathrm{M} \mathrm{KHCO}_{3}+\left(0.0167 \mathrm{M} \mathrm{K}_{2} \mathrm{CO}_{3} ;(\Delta) 0.075 \mathrm{M} \mathrm{KHCO}_{3}+0.005 \mathrm{M} \mathrm{K}_{2} \mathrm{CO}_{3}\right.$. 


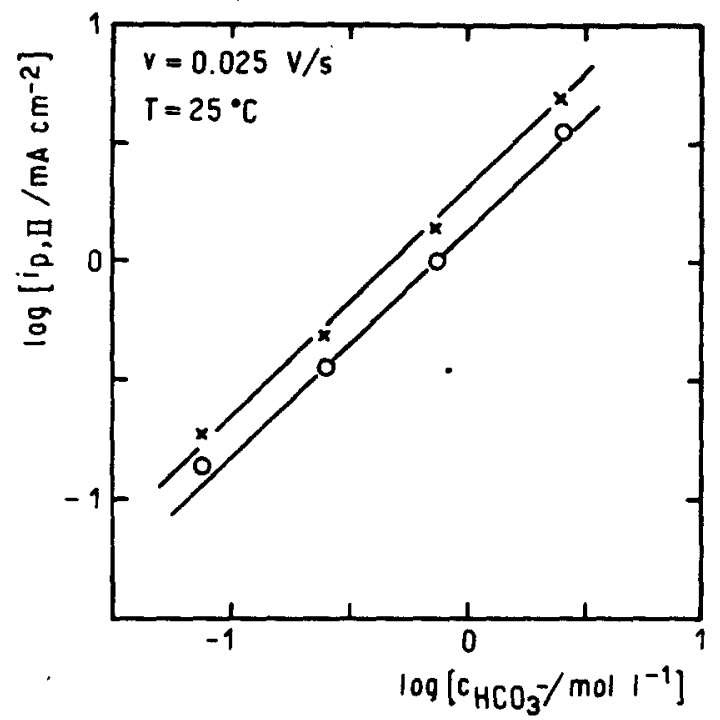

Fig. 5. The influence of the strength concentrations of $\mathrm{HCO}_{3}$ ion at $\mathrm{pH} 8.9$ on $i_{\mathrm{p} .11}$ resulting for $v=0.025 \mathrm{~V} / \mathrm{s}$ and $T=25^{\circ} \mathrm{C}$. ( $\left.\times\right) \omega=25(0) \mathrm{rpm} ;(0) \omega=10001 \mathrm{rpm}$.

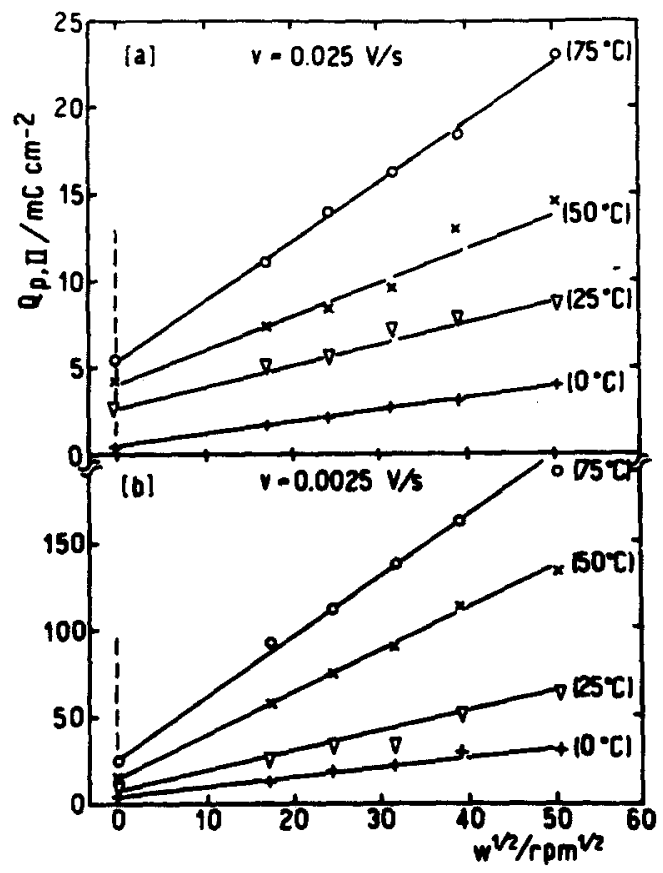

Fici. 6. The dependence of $Q_{\mathrm{p} .11}$ on $\omega$ at $T=0(+), 25(\nabla), 50(\times)$ and $75(0)^{\circ} \mathrm{C}$ in 0.75 $\mathrm{M} \mathrm{KHCO}:+0.05 \mathrm{M} \mathrm{K}_{2} \mathrm{CO}_{3}$ solution. (a) $\mathrm{v}=0.025 \mathrm{~V} / \mathrm{s}$ : (b) $v=0.0025 \mathrm{~V} / \mathrm{s}$. 


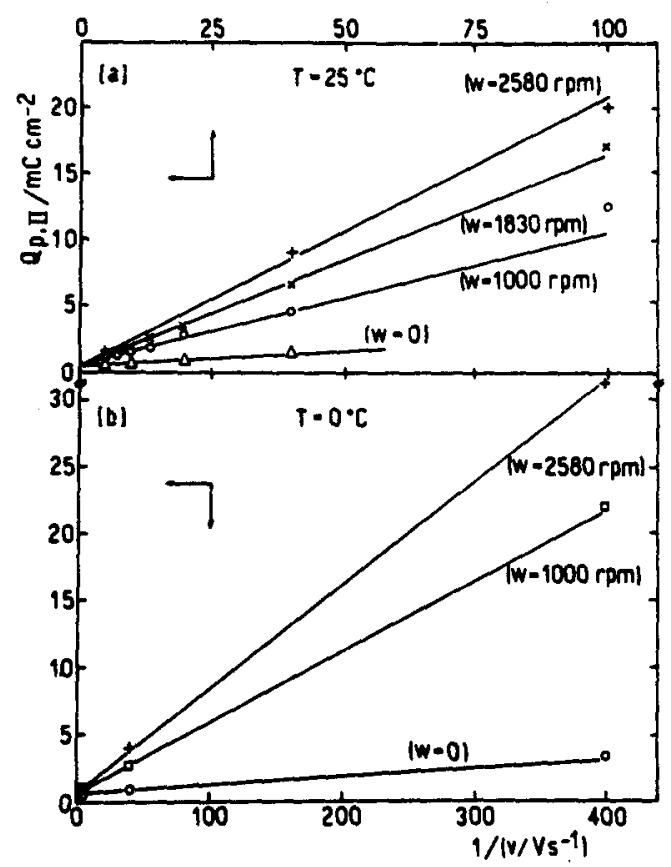

Fig. 7. The dependence of $Q_{\mathrm{p} .11}$ on $v$ at different $\omega$ in $0.75 \mathrm{M} \mathrm{KHCO}_{3}+0.05 \mathrm{M} \mathrm{K}_{2} \mathrm{CO}_{3}$ solution. (a) $T=25^{\circ} \mathrm{C}$; (b) $T=0^{\circ} \mathrm{C}$.

anodic charge increasing as $\omega$ increases. This effect can be related, in principle, to the decreasing stabilization of the passivating surface film. On the other hand, the hydrogen discharge current increases as $E_{\mathrm{s}, \mathrm{a}}$ is fixed at more positive values (Fig. 2b), this effect being more clearly distinguishable as $\omega$ decreases. In this case the negatively directed voltammogram can be taken as an indication of the extent of stabilization of the anodic surface products. Furthermore, at a constant $\omega$, the contours of peaks I, II and V become practically independent of $E_{\mathrm{s}, \mathrm{a}}$.

In the $0-75^{\circ} \mathrm{C}$ range, the height of peak II after passive current baseline correction increases linearly with $\omega^{1 / 2}$ (Fig. 3). This relationship holds in the whole range of $v$ covered in this work. At constant $v, T$ and $\mathrm{pH}$, a linear height of peak II vs $\omega^{1 / 2}$ relationship is observed (Fig. 4); the slopes of the straight lines increase according to the ionic strength of the solutions. The lines, however, do not intercept the origin of the co-ordinates as peak II is recorded also in still solutions (Fig. 1). In the $0-75^{\circ} \mathrm{C}$ range, at constant $\mathrm{pH}, v$ and $\omega$, the height of peak II increases linearly with the first order of $\mathrm{KHCO}_{3}$ (or $\mathrm{K}_{2} \mathrm{CO}_{3}$ ) concentration in solution (Fig. 5). These results indicate that peak $\mathrm{II}$ is, in principle, mainly related to a process under mass transport control.

On the other hand, at a constant voltage, the charge $\left(Q_{\mathrm{p} . \mathrm{II}}\right)$ related to peak II increases linearly with $\omega^{1 / 2}$ (Fig, 6), but at a constant $\omega$, it increases linearly with $v^{-1}$ (Fig. 7). For the latter, the value $Q_{\mathrm{p} .11}$ extrapolated to $v \rightarrow \infty$ is $0.7 \mathrm{mC} \mathrm{cm}^{-2}$. This charge can be assigned to the formation of the first passivating layer through an 


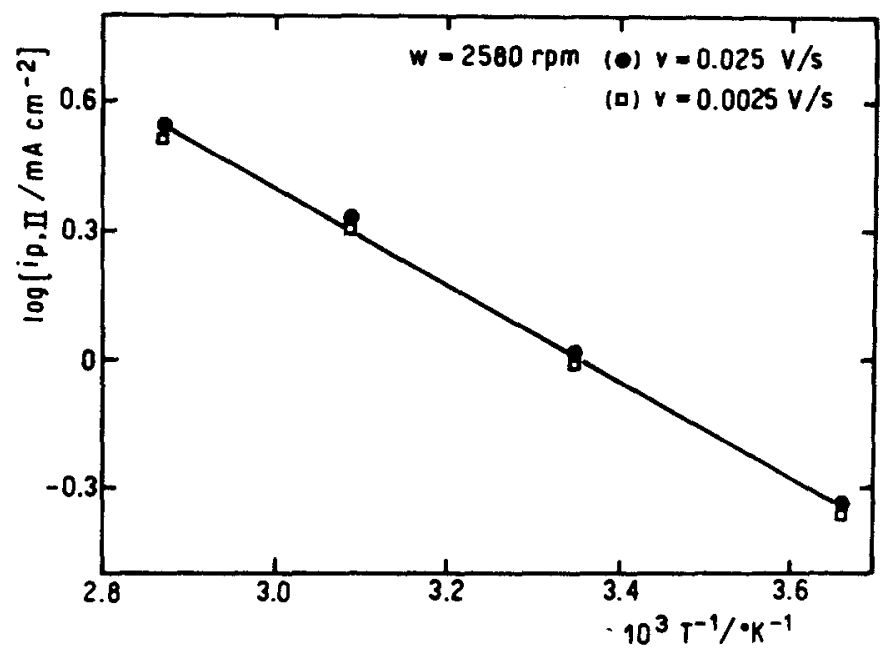

FIG. 8. Arrhenius plot corresponding to $i_{\mathrm{n} .11} . \omega=2580 \mathrm{rpm} ; 0.75 \mathrm{M} \mathrm{KHCO}_{3}+0.05 \mathrm{M}$ $\mathrm{K}_{2} \mathrm{CO}_{3}$ solution. $(\bullet) v=0.025 \mathrm{~V} / \mathrm{s} ;(\square) v=0.0025 \mathrm{~V} / \mathrm{s}$.

electrochemical reaction free of mass transport contribution. As the number and distribution of peaks in the voltammograms remain the same in the $0-75^{\circ} \mathrm{C}$ range, an apparent activation energy value $\left(\Delta E^{*}\right)$ for the electrochemical process associated with peak II can be estimated. For this purpose, the value $i_{\mathrm{p} . \mathrm{II}}$ at $\omega=0$ was subtracted from the value of $i_{\mathrm{p} \text {.II }}$ measured at each $\omega$. The corresponding Arrhenius plot at a constant $\omega$ is independent of $v$ (Fig. 8), and from the slope of the straight line it results $\Delta E^{*}=5.2 \mathrm{~kJ} \mathrm{~mol}^{-1}$, independently of $\omega$.

SEM observations performed on specimens previously held for $60 \mathrm{~min}$ at a constant potential in the potential range of peak II show considerable differences in the characterstics and distribution of surface products whether they were formed in still (Fig. 9a) or stirred solution (Fig. 9b). Energy dispersive X-ray analysis indicates, besides the presence of iron, traces of potassium, while electron probe micro-analysis indicates the presence of carbon and traces of potassium in the anodic film. These qualitative results can be related to the presence of carbonate species in the film formed on corroded iron in the active to passive transition region.

\section{DISCUSSION}

Voltammetric data show two anodic peaks in the potential range of the activepassive transition of iron in the carbonate-bicarbonate electrolytes. This suggests that the corresponding complex reaction involves at least two stages. The first stage, which is associated with peak I, appears as a surface process which is nearly temperature independent and involves a charge no greater than $1.0 \mathrm{mC} \mathrm{cm}^{-2}$. This relatively small charge can be assigned to the formation of the prepassive layer. ${ }^{29,30}$ The second stage, which is related to peak II, implies a mass transport contribution from the solution side which is coupled to the proper electrochemical reaction.

The first anodic stage occurs in the potential range where, according to bulk thermodynamics data, ${ }^{7.31 .32}$ only $\mathrm{Fe}$ (II) species are expected as reaction products. 
Therefore, the onset of the prepassive layer should principally correspond to a hydrous ferrous hydroxide layer. The latter can be produced through a complex reaction pathway formally written as follows: ${ }^{26}$

$$
\begin{aligned}
\mathrm{Fe}+\mathrm{H}_{2} \mathrm{O} & =\mathrm{Fe}(\mathrm{OH})+\mathrm{H}^{+}+e^{-} \\
\mathrm{Fe}(\mathrm{OH}) & =\mathrm{Fe}(\mathrm{OH})^{+}+e^{-} \\
\mathrm{Fe}(\mathrm{OH})^{+}+\mathrm{OH}^{-} & =\mathrm{Fe}(\mathrm{OH})_{2} \rightarrow \text { hydrous } \mathrm{Fe}(\mathrm{OH})_{2} \text { layer. }
\end{aligned}
$$

The initial step (1a) is the underpotential decomposition of water yielding $\mathrm{OH}$ adsorbed species; step (1b) implies the formation of the intermediate $\mathrm{FeOH}^{+}$which later neutralizes in the base solution, finally yielding the hydrous ferrous hydroxide layer. The electroformation of the initial $\mathrm{FeOH}$ species was recently detected through the triangularly modulated triangular potential sweep technique ${ }^{26,30}$ and the scratched surface method in rotating disc assembly. ${ }^{33}$

The coverage of the iron surface by the hydrous $\mathrm{Fe}(\mathrm{OH})_{2}$ layer caused the current decrease when the potential of peak $I$ is exceeded.

The second anodic stage takes place in the -0.4 to $-0.6 \mathrm{~V}$ range where only $\mathrm{Fe}$ (II) species can, in principle, be formed. The formation of $\mathrm{Fe}$ (III) species is observed when the applied potential is greater than $-0.3 \mathrm{~V} \cdot{ }^{14,25}$ Therefore, peak II can be ascribed to the electrodissolution of iron through the prepassive layer. This reaction increases both the thickness of the prepassive layer and the concentrations of $\mathrm{Fe}^{2+}$ and anions at the electrode-solution interface. When the concentration of these ions exceeds the saturation value of $\mathrm{FeCO}_{3}$, the latter is formed at the interface. This means that the complex nature of the process related to peak II as deduced from the influence of the potential scan rate and stirring on both its height (Figs 3 and 4) and charge (Figs 6 and 7), should result from at least three processes occurring simultaneously within the potential range of peak II. The first process increases the thickness of the $\mathrm{Fe}(\mathrm{OH})_{2}$ layer as deduced from the electroreduction charge recorded during the reverse potential scan in the negative potential excursion. The second process corresponds to the precipitation of $\mathrm{FeCO}_{3}$, which implies the electrodissolution of iron as $\mathrm{Fe}^{2+}$ takes place through the prepassive layer. Therefore, in the potential range of peak II a complex layer structure should be accomplished, involving as a limiting structure an inner hydrous $\mathrm{Fe}(\mathrm{OH})_{2}$ layer and an outer $\mathrm{FeCO}_{3}$ layer in contact with the solution. Finally, the third process is the partial removal of $\mathrm{FeCO}_{3}$ from the surface by a chemical reaction. These three reactions can be written as follows:

$$
\begin{aligned}
\mathrm{Fe}_{x}\left\{n\left[\mathrm{Fe}(\mathrm{OH})_{2} \cdot z \mathrm{H}_{2} \mathrm{O}\right]\right\} & +\left(2+z^{\prime}-z\right) \mathrm{H}_{2} \mathrm{O} \\
& =\mathrm{Fe}_{x-1}\left\{(n+1)\left[\mathrm{Fe}(\mathrm{OH})_{2} \cdot z^{\prime} \mathrm{H}_{2} \mathrm{O}\right\}+\left(2 \mathrm{H}^{+}\right)_{i}+2 e^{-}\right. \\
\mathrm{Fe}_{x}\left\{n\left[\mathrm{Fe}(\mathrm{OH})_{2} \cdot z \mathrm{H}_{2} \mathrm{O}\right]\right\} & =\mathrm{Fe}_{x-1}\left\{n\left[\mathrm{Fe}(\mathrm{OH})_{2} \cdot z \mathrm{H}_{2} \mathrm{O}\right]\right\}+\left(\mathrm{Fe}^{2+}\right)_{i}+2 e^{-} \\
\left(\mathrm{Fe}^{2+}\right)_{i}+\left(\mathrm{CO}_{3}^{2-}\right)_{i} & =\left(\mathrm{FeCO}_{3}\right)_{i}
\end{aligned}
$$

where the parentheses denote the anodic layer and the subscript $i$ refers to species at the interface. The rate of reaction (2) which corresponds to the thickening of the prepassive layer is given by the current density $i_{2}$. The rate of reaction (3), which implies the electrodissolution of base iron through the prepassive layer, is denoted by $i_{3}$. In this case, once the supersaturation of $\mathrm{FeCO}_{3}$ at the interface is reached, the 


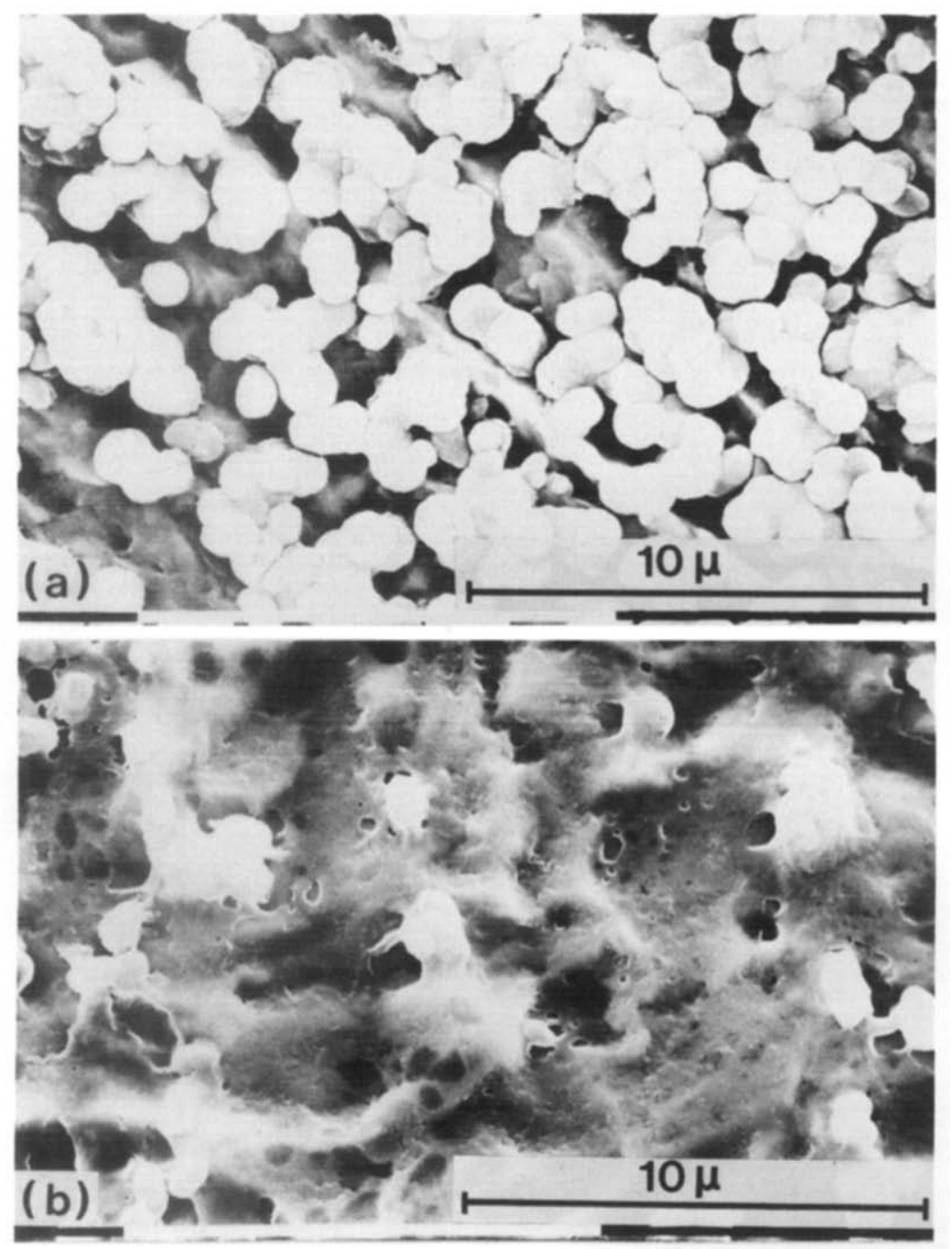

FiG. 9. Scanning electron micrographs of polycrystalline iron specimens holding the potential at $E_{\mathrm{p} .11}$ during $60 \mathrm{~min}$ in $0.75 \mathrm{M} \mathrm{KHCO}_{3}+0.05 \mathrm{M} \mathrm{K}_{2} \mathrm{CO}_{3}$ solution at $25^{\circ} \mathrm{C}$. (a) $\omega=0$; (b) $\omega=2580 \mathrm{rpm}$. 